\title{
Displacement of Oil in a Porous Medium on Diphasic Flow by Water Injection
}

\author{
Mmadi Salim Mohamed, Sosse Ndyaye, Kharouna Talla, Cheikh Mbow, Aboubaker Chedikh Beye \\ Department of Physics, Faculty of Science and Technics, Cheikh Anta Diop University, Dakar, Senegal \\ Email:salimaxe@yahoo.fr
}

How to cite this paper: Mohamed, M.S. Ndyaye, S., Talla, K., Mbow, C. and Beye, A.C. (2020) Displacement of Oil in a Porous Medium on Diphasic Flow by Water Injection. Open Journal of Fluid Dynamics, 10, 1-7. https://doi.org/10.4236/ojfd.2020.101001

Received: October 1, 2019

Accepted: December 27, 2019

Published: December 30, 2019

Copyright (c) 2020 by author(s) and Scientific Research Publishing Inc. This work is licensed under the Creative Commons Attribution International License (CC BY 4.0).

http://creativecommons.org/licenses/by/4.0/

(c) (i) Open Access

\begin{abstract}
The purpose of this article is to show the role and influence of fluid injection, porosity on two-phase flows in porous media for the purpose of improving and increasing recovery efficiency assisted by oil. An experimental study was carried out in porous media, it is a plexiglass cylinder filled with sands saturated with crude oil. Pressure drop and data processing for two-phase flow are measured and processed using a differential pressure sensor connected to an acquisition computer. It thus makes it possible to determine the pressure difference between the inlet and the outlet of the porous medium over time. In this experiment, the flow rates at the inlet and the outlet of the porous medium were measured as a function of time using a flow rate and a pump. To describe these flows we will use Darcy's model.
\end{abstract}

\section{Keywords}

Two-Phase Flow, Enhanced Recovery, Oil, Permeability, Porous Media

\section{Introduction}

The high energy consumption induces a scarcity of hydrocarbon resources, forcing us to work in extreme conditions with increasingly difficult operating conditions (difficult reservoirs, depth, etc.)

This requires more advanced recovery techniques in which complex fluids find their place.

In fact, the recovery of hydrocarbons uses several complex fluids that are the hydrocarbons themselves and the different types of fluids (liquid water and water vapor, gases such as carbon dioxide and dinitrogen) used in different methods of recovery.

Complex fluids are used during the different phases of the production process. The stimulation of the porous medium is done by injecting through a well into 
the subterranean formation under high pressure so as to overcome the main stress of the rock and cause a crack in the porous medium. When fracture pressure is exceeded, very penetrating cracks or drainage ditches are initiated and propagated [1].

An oil field is not, as is often interpreted by the public, an underground lake where it is enough to draw, but it is a rock which contains the oil in its pores: these being sufficiently small (capillaries). Extracting this viscous liquid is not easy in practice. From then on the exploitation of an oil field is carried out according to several stages that are indicated by an order (possibly) chronological:

1) Primary recovery:

When the oil spontaneously arrives at the surface thanks to the presence of compressed gas, or to the differences of hydrostatic pressure: the quantities during this phase are generally small $(5 \%-10 \%)$ compared to the potentialities of the deposit.

2) Secondary recovery:

It consists of using methods that do not modify the physico-chemical properties of the oil, but that replaces it with another fluid, necessarily cheaper. We distinguish between the use of submerged pumps, the injection of water and the injection of the formation gas or other miscible gases (nitrogen, $\mathrm{CO}_{2}$ ) [2] [3], the latter two processes that we intend to address within this context research work.

3) Tertiary (or improved) recovery:

Here the physico-chemical properties of the oil will be modified, for example by lowering the viscosity of the oil or facilitating its mobility in the deposit. These results are obtained by injecting water vapor, heat, $\mathrm{CO}_{2}$, immiscible gases, or even more surfactants and polymers. Other methods, such as the injection of microorganisms capable of reducing the length of hydrocarbon chains and of producing in situ surfactants and $\mathrm{CO}_{2}$, have been proposed. Assisted Recovery is sometimes referred to as the combination of the last two steps. Be that as it may, it is the study of the reservoir and the oil and the natural means on the spot that will determine the nature of the actions to be carried out [4].

\section{Experimental Study}

\subsection{Preparation of the Sample}

The various porous media used consist of different sizes of sand ranging from $0.05 \mathrm{~mm}$ to $4 \mathrm{~mm}$ in diameter. The preparation of the samples consists of filling a plexiglass cylinder of internal diameter equal to $95 \mathrm{~mm}$, outer diameter 100 $\mathrm{mm}$ and $50 \mathrm{~cm}$ long. On both sides of the cylinder are fitted injectors provided with O-rings to ensure the sealing of the medium. The injectors are fitted with a valve for connection to the injection pump and pressure taps for pressure drop measurements, see Figure 1.

\subsection{Experimental Protocol}

1) Saturation of the sample with light oil; 


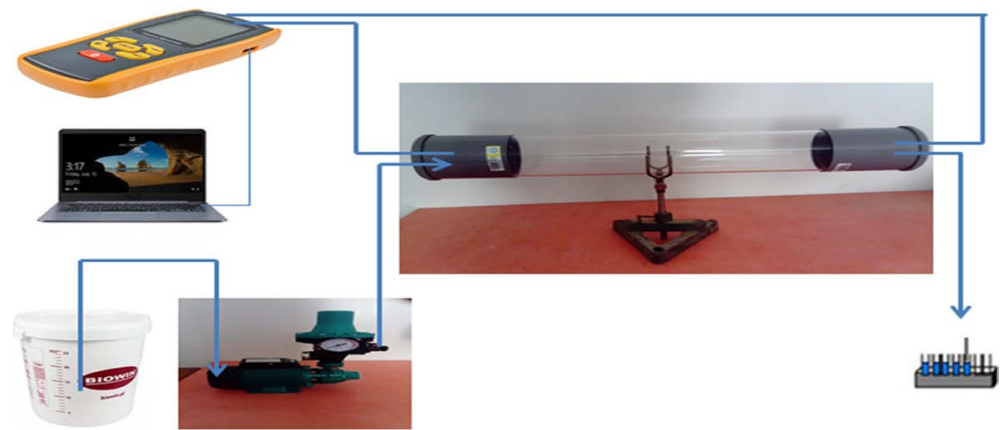

(a)

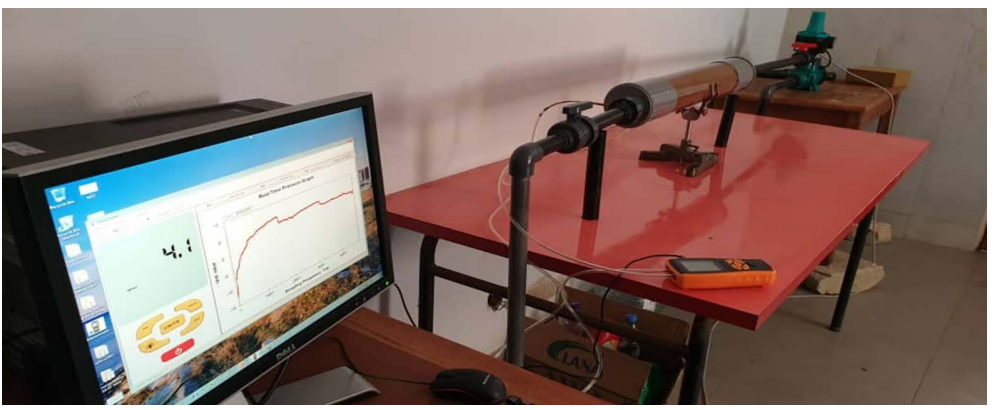

(b)

Figure 1. Experimental schema (a) and (b) permanent flow, the pressure stabilizes at 4.1 mbar. (a) Experimental device; (b) Experimental measurement.

2) Know the influence of porosity using sand of different diameters in the porous medium;

3) Determination of the water permeability by measuring pressure loss between 0 and 900 mbar using the pressure sensor;

4) Impose a flow rate between 0 and $600 \mathrm{ml} / \mathrm{min}$ using the pump;

5) The measurements made are stored on a computer via an acquisition card controlled by a suitable software;

6) A fraction collector is used to collect the volume of oil displaced.

\section{Equations and Models}

Consider the two-phase flow for these two immiscible fluids, water and oil.

The independent variables are:

-for both fluids: densities $\rho_{\mathrm{w}}$ and $\rho_{o}$, interfacial tension $\sigma$, the viscosity $\mu_{\mathrm{w}}$ and $\mu_{o}$, the wettability coefficient in the form $\cos (\theta)$, filtration speeds $v_{w}$ (water) and $v_{o}$ (oil) for the porous medium: the pore radius, the shape factor, the characteristic length $\mathrm{L}$.

The porous medium is confined in a cylinder mounted horizontally, the external forces related to the gravity are negligible. Unlike monophasic flows, two-phase flows, when we neglect the effects related to gravity, we must take into account the phenomena complex physic-chemicals at the interfaces of the two fluids and in contact with the fluids with the matrix.

It does not exist in general, in the flow, a sharp front through which we pass abruptly from one fluid to another, but a transition zone, in which the two fluids 
move simultaneously and the capillary forces play a very large role.

We must therefore take this phenomenon into account in a global way by introducing a macroscopic capillary pressure. We start from the equation system representing two-phase displacement in a porous medium. This system consists of the equations of motion (generalized Darcy's law) [5]:

$$
\begin{gathered}
\vec{v}_{w}=-k \frac{k_{w}}{\mu_{w}} \overrightarrow{\operatorname{grad}}\left(p_{w}+\rho_{w} g z\right) \\
\vec{v}_{0}=-k \frac{k_{0}}{\mu_{0}} \overrightarrow{\operatorname{grad}}\left(p_{0}+\rho_{0} g z\right)
\end{gathered}
$$

where $k_{w}$ and $k_{0}$ are called the relative permeabilities of water and oil that we assume that they are only a function of the saturation $S$ of one of the two fluids, water for example.

Consider the conservation equations of mass:

$$
\begin{gathered}
\operatorname{div}(\vec{v})=0 \\
\Phi \frac{\partial s}{\partial t}+\operatorname{div}\left(\vec{v}_{w}\right)=0 \\
\text { With } \vec{v}=\vec{v}_{w}+\vec{v}_{o}
\end{gathered}
$$

where $\vec{v}$ is the total filtration rate and $\Phi$ porosity. The pressures $P_{w}$ and $p_{o}$ in the two phases are connected via the capillary pressure $p_{c}$ : $P_{w}=p_{o}-p_{c}$ where $p_{c}$ is assumed only depending on saturation S. by eliminating $P_{w}, p_{o}, \vec{v}_{w}, \vec{v}_{o}$ and $\operatorname{div}\left(\vec{v}_{w}\right)$ between Equations ((1)-(4) and (5)), we obtain:

$$
\begin{aligned}
& \Phi \frac{\partial s}{\partial t}+\frac{\mathrm{d} \xi}{\mathrm{d} s}\left(u \frac{\partial s}{\partial x}+v \frac{\partial s}{\partial y}+\frac{\partial s}{\partial z}\right) \\
& +\frac{k}{\mu_{o}}\left[\frac{\partial}{\partial x}\left(\eta \frac{\mathrm{d} p_{c}}{\mathrm{~d} s} \frac{\partial s}{\partial x}\right)+\frac{\partial}{\partial y}\left(\eta \frac{\mathrm{d} p_{c}}{\mathrm{~d} s} \frac{\partial s}{\partial y}\right)+\frac{\partial}{\partial z}\left(\eta \frac{\mathrm{d} p_{c}}{\mathrm{~d} s} \frac{\partial s}{\partial z}\right)\right] \\
& -\frac{k}{\mu_{o}} g \Delta \rho \frac{\mathrm{d} \eta}{\mathrm{d} s} \frac{\partial s}{\partial z}=0
\end{aligned}
$$

where $\xi=\left(1+\frac{k_{o}}{k_{w}} \frac{\mu_{w}}{\mu_{o}}\right)^{-1}, \Delta p=p_{w}-p_{o}$, and $\eta=k_{o} \xi$ are dimensionless functions of saturation $\mathrm{S}$.

\section{Results and Discussion}

Figure 2 shows that this pressure drop decreases after 300 seconds and then increases over time according to the number of water volume injected without stabilizing, see Figure 2(a) and Figure 2(b). In addition, the volumes of water and oil recovered at the outlet of the porous medium vary according to the size of the sand grains used. This suggests that the porous medium retains oil depending on the nature of the porous medium either by adsorption or by trapping by the pores [6] [7]. 
In these two-phase flows, the transport of oil-lubricated oils is based on the natural phenomenon in which a less viscous phase migrates to the high-shear region near the cylinder wall used at the laboratory scale, where it lubricates the flow less well for sand with a diameter of less than $2 \mathrm{~mm}$ whose friction forces are important (more oil trapping in the rock), than sand with a diameter greater than $2 \mathrm{~mm}$ whose friction forces become less important (less than trapping of oil in the rock), see Table 1. Once pumping pressures are balanced by wall shear, see Figure 3 whose pressure stabilizes from 1650 seconds, lubricated transport requires pressures comparable to pumping water alone, regardless of oil viscosity.

The phases of oil and water can be organized differently during pumping. The porous medium is placed horizontally, these flows are stratified based on the density of water and oil [8].

Transitional regime
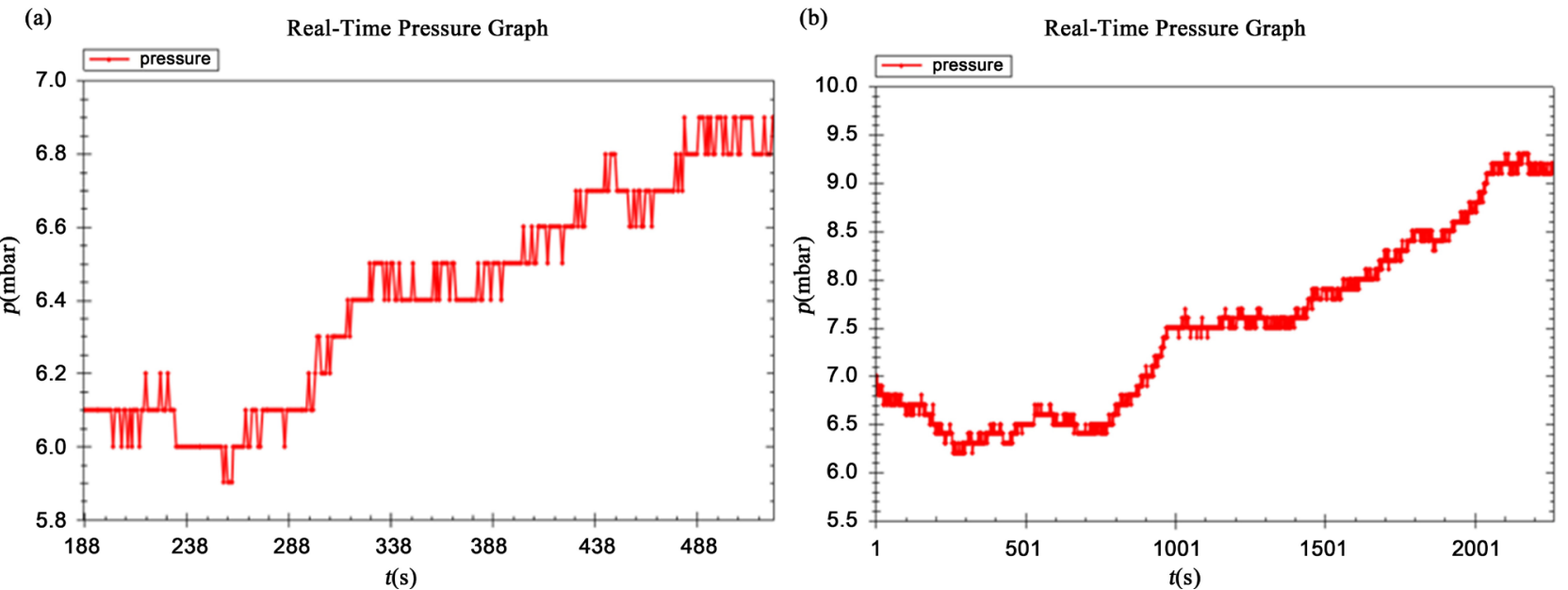

Figure 2. (a) and (b) pressure loss as a function of time.

Table 1. Volume of oil displaced as a function of time for different diameter of sand used.

\begin{tabular}{cccc}
\hline $\mathrm{Vp}(\mathrm{ml})$ & Temps $(\mathrm{min})$ & Débit d'eau q $(\mathrm{ml} / \mathrm{min})$ & Diamètre du sable $\mathrm{D}(\mathrm{mm})$ \\
\hline 14.9 & 30 & 1.67 & $0.05<\mathrm{D}<0.5$ \\
26.5 & 60 & 1.67 & $0.05<\mathrm{D}<0.5$ \\
31.5 & 75 & 1.67 & $0.05<\mathrm{D}<0.5$ \\
54.2 & 120 & 1.67 & $0.05<\mathrm{D}<0.5$ \\
19.4 & 30 & 1.67 & $0.5<\mathrm{D}<2$ \\
35.7 & 60 & 1.67 & $0.5<\mathrm{D}<2$ \\
38.6 & 75 & 1.67 & $0.5<\mathrm{D}<2$ \\
72.4 & 120 & 1.67 & $0.5<\mathrm{D}<2$ \\
23.6 & 30 & 1.67 & $2<\mathrm{D}<4$ \\
44.3 & 60 & 1.67 & $2<\mathrm{D}<4$ \\
52.7 & 75 & 1.67 & $2<\mathrm{D}<4$ \\
85.1 & 120 & 1.67 & $2<\mathrm{D}<4$ \\
\hline
\end{tabular}




\section{Conclusions and Perspectives}

The physico-chemical methods of improved recovery of oil allow increasing the production of oil by adding agents (polymers, water, gases ...) acting on different physical parameters.

Figure 4 shows that a limiting factor concerns the nature and properties of the porous medium. Our experiments have shown that we need to use porous media with sand greater than $4 \mathrm{~mm}$ in diameter to reduce oil entrapment and efficiently move oil into the porous medium.

The perspectives of this study concern several points which it would be interesting to go into further.

Firstly, it would be judicious, experimentally, to inject polymers in the porous medium which will allow us to increase the viscosity of the displacing fluid, which would lead, during the injection, to a reduction of the instabilities of front, modifying the wettability of the rock to hope to decrease the water-oil interfacial tension and to remobilize oil drops trapped by the capillary effects [9] [10] [11] [12].

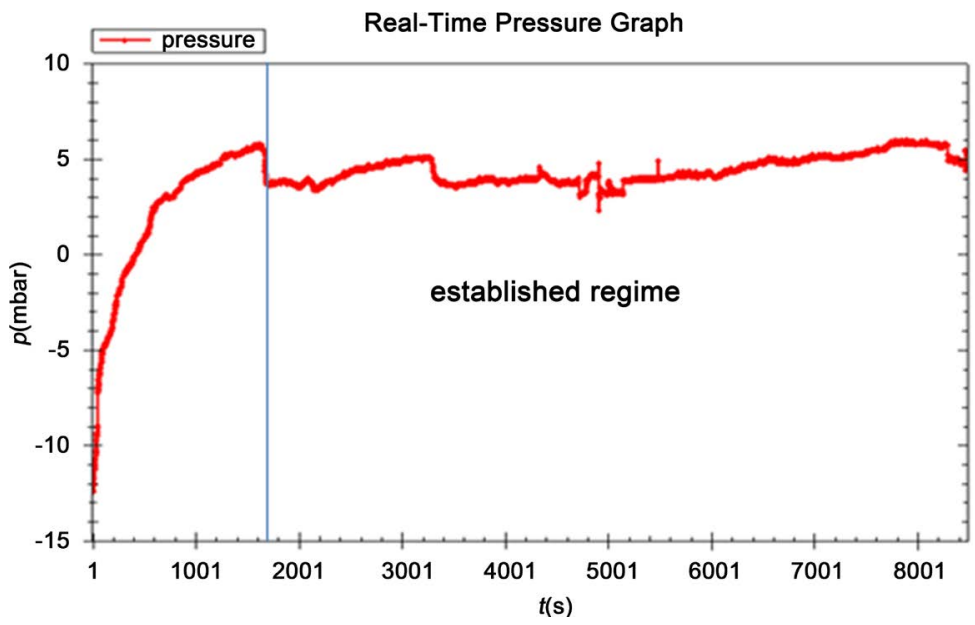

Figure 3. Established regime, the pressure stabilizes at 5 mbar after 35 hours.

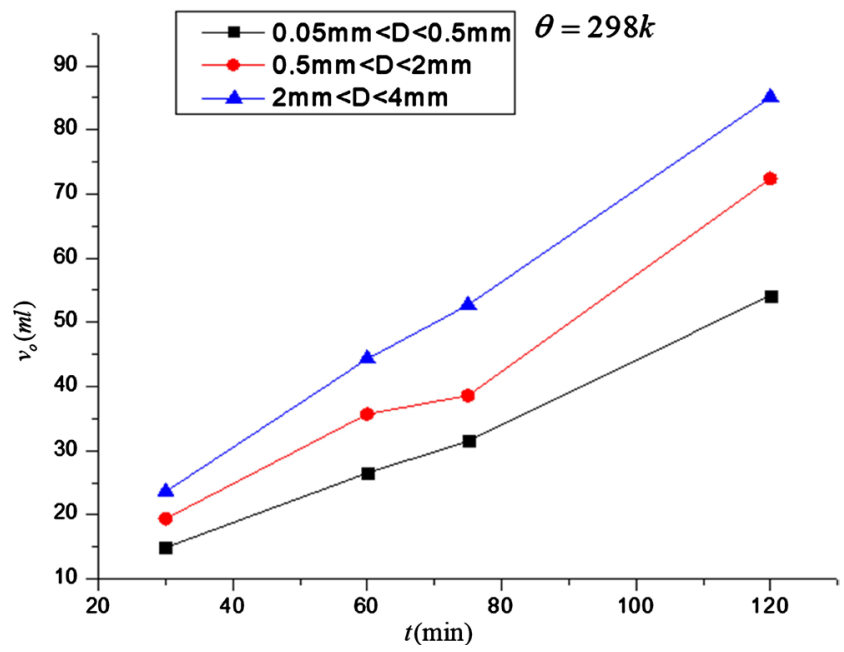

Figure 4. Representation of the volume of oil recovered for each size of sand grains as a function of time. 


\section{Conflicts of Interest}

The authors declare no conflicts of interest regarding the publication of this paper.

\section{References}

[1] Yang, J. (2002) Viscoelastic Wormlike Micelles and Their Applications. Current Opinion in Colloid \& Interface Science, 7, 276-281. https://doi.org/10.1016/S1359-0294(02)00071-7

[2] Lake, L.W. (1989) Enhanced Oil Recovery. Prentice Hall, Englewood Cliffs, NJ.

[3] Bedrikovetsky, P.G. (1993) Mathematical Theory of Oil \& Gas Recovery (with Applications to Ex-USSR Oil \& Gas Condensate Fields). Kluwer Academic Publishers, London-Boston-Dordrecht.

[4] Baker, P.E. and Gould, G.D. (1966) Method of Assisted Oil Recovery. U.S. Patent No. 3,252,512.

[5] Al-Wahaibi, T., Yusuf, N., Al-Wahaibi, Y. and Al-Ajmi, A. (2012) Experimental Study on the Transition between Stratified and Non-Stratified Horizontal Oil-Water Flow. International Journal of Multiphase Flow, 38, 126-135. https://doi.org/10.1016/j.ijmultiphaseflow.2011.08.007

[6] Engelberts, W.F. and Klinkenberg, L.J. (1951) Laboratory Experiments on the Displacement of Oil by Water from Packs of Granular Material. 3rd World Petroleum Congress, Hague, the Netherlands, 28 May-6 June 1951, WPC-4138.

[7] Wang B., Wu T., Li, Y.J., Sun, D.J., Yang, M., Gao, Y.X., et al. (2011) The Effects of Oil Displacement Agents on the Stability of Water Produced from ASP (Alkaline/Surfactant/Polymer) Flooding. Colloids and Surfaces A: Physicochemical and Engineering Aspects, 379, 121-126. https://doi.org/10.1016/j.colsurfa.2010.11.064

[8] AL-Yaari, M.A. and Abu-Sharkh, B.F. (2011) CFD Prediction of Stratified Oil-Water Flow in a Horizontal Pipe. Asian Transactions on Engineering, 1, 68-75.

[9] Taylor, K.C. and Nasr-El-Din, H.A. (1998) Water-Soluble Hydrophobically Associating Polymers for Improved Oil Recovery: A Literature Review. Journal of Petroleum Science and Engineering, 19, 265-280. https://doi.org/10.1016/S0920-4105(97)00048-X

[10] Samanta, A., Achinta, B., Keka, O. and Mandal, A. (2012) Comparative Studies on Enhanced Oil Recovery by Alkali-Surfactant and Polymer Flooding. Journal of Petroleum Exploration and Production Technology, 2, 67-74. https://doi.org/10.1007/s13202-012-0021-2

[11] Kamari, A., Sattari, M., Mohammadi, A.H., et al. (2015) Méthode fiable pour la détermination de la rétention de surfactant dans les milieux poreux lors de la récupération de pétrole par inondation chimique. Carburant, 158, 122-128.

[12] Cheraghian, G. and Hendraningrat, L. (2016) A Review on Applications of Nanotechnology in the Enhanced Oil Recovery Part A: Effects of Nanoparticles on Interfacial Tension. International Nano Letters, 6, 129-138. https://doi.org/10.1007/s40089-015-0173-4 